\title{
Pengaruh Beberapa Tingkatan Suhu Ruang terhadap Waktu Perkembangan Cryptolestes ferrugineus Stephens
}

\section{Effect of Several Level Room Temperatures on the Time Development of Cryptolestes ferrugineus Stephens}

\author{
Ni Putu Eka Pratiwi*, Komang Dean Ananda \\ Fakultas Pertanian, Universitas Mahasaraswati Denpasar, Jalan Kamboja No 11 A Denpasar Indonesia \\ *Corresponding authors: ekkapratiwi93@gmail.com
}

\begin{abstract}
Cryptolestes ferrugineus (Cucujidae: Laemophloeidae) is a postharvest secondary pest of rice and other food commodity products. The distribution of $C$. ferrugineus covers tropical or subtropical climates with high humidity. Temperature fluctuations that occur every day affect development $C$. ferrugineus. The development of the life phase of $C$. ferrugineus largely determines the amount of its population and its massive impact on the damage caused to storing material. This research was conducted to determine the effect of several levels of room temperature on the development time of $C$. ferrugineus. The room temperature used in this study was $20^{\circ} \mathrm{C}, 25^{\circ} \mathrm{C}, 30^{\circ} \mathrm{C}, 35^{\circ} \mathrm{C}$, and $40^{\circ} \mathrm{C}$ and was repeated five times. The results showed that the shortest development time of the insect pest $C$. ferrugineus (26.75 days) occurred at a room temperature of $30^{\circ} \mathrm{C}$ with a humidity of $68 \%$ compared to other room temperatures. The slowest development time for $C$. ferrugineus occurs at $25^{\circ} \mathrm{C}$ (42.60 days). At room temperature $40^{\circ} \mathrm{C}$ eggs produced by adult female $C$. ferrugineus cannot develop into larvae, so the development $C$. ferrugineus at $40^{\circ} \mathrm{C}$ was cut off
\end{abstract}

Keywords: Cryptolestes ferrugineus, Temperature, Time Development

\section{PENDAHULUAN}

Beras yang merupakan komoditas utama bagi sebagian besar masyarakat Indonesia, menjadikannya sebagai sumber makanan pokok. Sebagai negara agraris, Indonesia dapat mandiri secara pangan, khususnya dalam produksi padi. Oleh karena itu, proses pascapanen padi yang terdiri dari pemanenan hasil dan pemrosesan gabah hingga siap didistribusikan ke konsumen, harus dilakukan secara optimum. Dalam proses tersebut, penyimpanan menjadi fokus utama karena pada periode tersebut padi dapat mengalami penurunan kualitas dan kuantitas (Andales, 1998; Syarief dan Halid, 1993). Selama proses penyimpanan, beras dapat mengalami penurunan kuantitas dan kualitas yang disebabkan oleh serangan hama pascapanen, khususnya hama gudang. Salah satu hama gudang yang menyerang beras yaitu, Cryptolestes ferrugineus.

Serangga $C$. ferrugineus merupakan hama sekunder pascapanen pada komoditas beras dan produk komoditas pangan yang lain. Hama ini menyerang bahan simpan dalam bentuk butir pecah akibat serangan hama primer atau kerusakan akibat saat penyimpanan. Penyebaran $C$. ferrugineus meliputi daerah beriklim tropis atau iklim subtropis dengan kelembaban yang tinggi (Mason, 2003). Serangga hama gudang dapat bertahan hidup dibawah suhu optimum dan masing-masing spesies hama gudang memiliki respon berbeda dalam setiap suhu (Sinha dan Watters, 1985). Ketahanan hidup serangga hama gudang terhadap beberapa tingkatan suhu dipengaruhi oleh derajat suhu, durasi paparan, spesies, stadia perkembangan, diapause, kelembaban , umur dan kemampuan beradaptasi pada kondisi baru (Lee, 1991; Fields, 1992; Mason dan Strait, 1998; Eliopoulos et al., 2011). Fluktuasi suhu yang terjadi setiap hari mempengaruhi perkembangan hama gudang. Serangga hama gudang memiliki kisaran suhu optimum untuk perkembangan, apabila suhu optimum tersebut tidak terpenuhi maka akan terjadi penambahan waktu perkembangan (Rees, 2004).

Serangga hama gudang $C$. ferrugineus dapat bertahan hidup dan berreproduksi di tempat penyimpanan. Imago betina $C$. ferrugineus meletakkan telur 2-3 butir perhari pada biji atau bahan simpan di tempat penyimpanan (Rillet, 1949; Smith, 1965). Telur akan menetas 4-5 hari setelah diletakkan pertama kali dan menyelesaikan siklus hidupnya selama 3 minggu dengan suhu optimum $35^{\circ} \mathrm{C}$ dan kelembaban $70 \%$ (Smith, 1965). Imago $C$. ferrugineus memiliki rata-rata masa hidup 6-9 bulan dan imago toleran terhadap suhu rendah jika dibandingkan dengan spesies serangga hama gudang lainnya (Fields dan White, 1997). Imago C. ferrugineus dapat bertahan hidup selama 4 minggu dalam kondisi suhu $-15^{\circ} \mathrm{C}$ (Fields, 1992). Imago $C$. ferrugineus lebih menyukai kondisi lingkungan dengan suhu yang hangat dan akan berada pada area tersebut untuk makan dan menginfestasi bahan simpan (Flinn dan Hagstrum, 1998; Jian et al., 2004). Perkembangan fase hidup $C$. ferrugineus sangat menentukan jumlah populasinya dan dampak masifnya terhadap kerusakan yang ditimbulkan pada bahan simpan. Oleh karena itu, perlu dilakukan beberapa perlakuan secara tepat untuk 
mengendalikan serangan tersebut dengan menghambat fase hidup C. ferrugineus. Salah satunya adalah dengan memberikan perlakukan beberapa tingkatan suhu ruang, untuk mengetahui efek paparan terhadap perkembangan C. ferrugineus.

\section{METODE}

\section{Pakan dan Strerilisasi Pakan}

Pakan yang digunakan dalam penelitian yaitu beras IR 64. Pakan disterilisasi menggunakan oven selama 4 jam dengan suhu $40^{\circ} \mathrm{C}$ kemudian didiamkan selama 24 jam pada suhu ruang $27^{\circ} \mathrm{C}$ hingga pakan tersebut siap untuk digunakan di dalam penelitian (Bekele et al., 1995).

\section{Perbanyakan Serangga}

Perbanyakan serangga $C$. ferrugineus dimulai dengan pemeliharaan yang dilakukan di dalam tabung perbanyakan dengan suhu $27^{\circ} \mathrm{C}$ dan kelembaban $70 \%$. Permukaan tabung ditutup menggunakan kain kasa. Setelah 7 hari infestasi, imago C. ferrugineus dipindahkan dari dalam tabung perbanyakan, kemudian ditunggu sampai imago F1 muncul untuk digunakan di dalam penelitian (Abebe et al., 2009).

\section{Waktu Perkembangan Telur, Larva dan Pupa $C$. ferrugineus}

Pelaksanaan penelitian menggunakan tabung kaca dengan ukuran $6,5 \mathrm{~cm}$ dan tinggi $9 \mathrm{~cm}$ berisi beras varietas IR 64 dan imago $C$. ferrugineus 15 pasang. Suhu yang digunakan dalam penelitian $20^{\circ} \mathrm{C}, 25^{\circ} \mathrm{C}, 30^{\circ} \mathrm{C}, 35^{\circ} \mathrm{C}$, dan $40^{\circ} \mathrm{C}$. Pengamatan waktu perkembangan telur C. ferrugineus dilakukan setelah 3 hari infestasi yang diletakkan dalam setiap tingkatan suhu. Jumlah pengamatan telur yang diamati minimal 10 butir dari setiap tingkatan suhu dan diletakkan pada cawan petri, lalu pengamatan umur telur dimulai pada hari ke-3 setelah telur di letakkan dalam cawan petri hingga menetas menjadi larva. Pengamatan waktu perkembangan larva yang diamati berasal dari telur yang menetas pada hari yang sama. Pengamatan larva dilakukan pada hari ke-6 setelah kemunculan larva pertama kali hingga menjadi pupa. Waktu perkembangan pupa yang diamati berasal dari larva yang pertama kali muncul menjadi pupa dan diletakkan pada tabung pengamatan yang sama. Pengamatan pupa dilakukan pada hari ke- 3 setelah muncul pupa pertama kali hingga muncul menjadi imago baru.

\section{ANALISIS DATA}

Rancangan yang digunakan dalam penelitian ini adalah Rancangan Acak Lengkap (RAL) yang dilakukan pengulangan perlakuan sebanyak 5 kali. Data yang diperoleh dianalisa menggunakan uji $\mathrm{F}$ dengan taraf 5\%. Apabila terdapat perbedaan diantara perlakuan dilanjutkan dengan Uji Beda Nyata Terkecil (BNT).

\section{HASIL DAN PEMBAHASAN}

Hasil analisis statistika terhadap waktu perkembangan telur, larva dan pupa $C$. ferrugineus menunjukkan bahwa tingkatan suhu ruang yang berbeda berpengaruh nyata. Pada variabel pengamatan waktu perkembangan telur, larva, dan pupa $C$. ferrugineus pada suhu $40^{\circ} \mathrm{C}$ tidak diikutkan dalam analisis statistika karena telur yang diletakkan pada suhu $40^{\circ} \mathrm{C}$ tidak menetas menjadi larva. Rerata waktu perkembangan telur, larva, dan pupa $C$. ferrugineus pada beberapa tingkatan suhu ruang disajikan pada Tabel 1 .

Tabel 1. Waktu Perkembangan Telur, Larva, dan Pupa C. ferrugineus pada Beberapa Tingkatan Suhu Ruang.

\begin{tabular}{cccccc}
\hline $\begin{array}{c}\text { Perlakuan } \\
\text { suhu }\end{array}$ & $\begin{array}{c}\text { Kelem- } \\
\text { baban }\end{array}$ & $\begin{array}{c}\text { Perkembangan } \\
\text { Telur } \\
\text { (Hari) }\end{array}$ & $\begin{array}{c}\text { Perkembangan } \\
\text { Larva } \\
\text { (Hari) }\end{array}$ & $\begin{array}{c}\text { Perkembangan } \\
\text { Pupa } \\
\text { (Hari) }\end{array}$ & $\begin{array}{c}\text { Perkembangan } \\
\text { Telur-Pupa } \\
\text { (Hari) }\end{array}$ \\
\hline $\mathbf{2 0}^{\circ} \mathbf{C}$ & $60 \%$ & $11,50 \mathrm{~b}$ & $18,00 \mathrm{a}$ & $11,00 \mathrm{~b}$ & $40,50 \mathrm{ab}$ \\
$\mathbf{2 5}^{\circ} \mathbf{C}$ & $70 \%$ & $6,25 \mathrm{ab}$ & $30,75 \mathrm{~b}$ & $5,50 \mathrm{ab}$ & $42,50 \mathrm{~b}$ \\
$\mathbf{3 0}^{\circ} \mathbf{C}$ & $68 \%$ & $4,50 \mathrm{a}$ & $18,25 \mathrm{a}$ & $4,00 \mathrm{ab}$ & $26,75 \mathrm{a}$ \\
$\mathbf{3 5}^{\circ} \mathbf{C}$ & $40 \%$ & $10,50 \mathrm{~b}$ & $19,00 \mathrm{a}$ & $2,50 \mathrm{a}$ & $32,00 \mathrm{a}$ \\
$\mathbf{4 0}^{\circ} \mathbf{C}$ & $35 \%$ & - & - & - & - \\
\hline
\end{tabular}



Hasil penelitian yang dilakukan menunjukkan bahwa rerata waktu perkembangan telur lebih singkat terjadi pada suhu $30^{\circ} \mathrm{C}$, daripada suhu $25^{\circ} \mathrm{C}$, suhu $35^{\circ} \mathrm{C}$, dan suhu $20^{\circ} \mathrm{C}$. Berdasarkan hasil penelitian Howe (1956), waktu perkembangan telur $T$. castaneum yang dinfestasikan pada suhu $30^{\circ} \mathrm{C}$ (3,6 hari). Rerata waktu perkembangan telur yang panjang terjadi pada suhu $20^{\circ} \mathrm{C}$ diduga karena telur yang terinfestasi pada suhu $20^{\circ} \mathrm{C}$ merupakan suhu minimum bagi $C$. ferrugineus sehingga waktu perkembangan yang dibutuhkan lebih panjang daripada suhu ruang yang lain. Kawamoto (1989), menyatakan bahwa telur $C$. ferrugineus dapat bertahan hidup pada suhu rendah namun akan mengalami dormansi sehingga memerlukan waktu yang lama untuk menetas menjadi larva. Berdasarkan hasil penelitian Abdelghany (2017) Imago $C$. ferrugineus tidak berkembang dengan normal namun tetap dapat bertahan hidup pada kondisi suhu yang rendah.

Berdasarkan hasil analisis statistika terhadap waktu perkembangan larva menunjukkan bahwa beberapa tingkatan suhu ruang yang berbeda berpengaruh nyata. Rerata waktu perkembangan larva lebih singkat terjadi pada suhu $20^{\circ} \mathrm{C}$, daripada suhu $30^{\circ} \mathrm{C}$, suhu $35^{\circ} \mathrm{C}$, dan suhu $25^{\circ} \mathrm{C}$. Howe (1956), menyatakan bahwa waktu perkembangan larva T. castaneum pada suhu $30^{\circ} \mathrm{C}$ ialah 17,2 hari, suhu $35^{\circ} \mathrm{C}$ ialah 19,7 hari dan suhu $25^{\circ} \mathrm{C}$ ialah 31,2 hari. Rerata waktu perkembangan larva lebih lama terjadi pada suhu $25^{\circ} \mathrm{C}$ daripada suhu ruang yang lain, hal tersebut terjadi karena suhu tersebut bukan suhu optimum bagi $C$. ferrugineus.

Berdasarkan hasil analisis statistika menunjukkan bahwa beberapa tingkatan suhu ruang berpengaruh nyata terhadap waktu perkembangan pupa $C$. ferrugineus. Rerata waktu perkembangan pupa lebih singkat terjadi pada suhu $35^{\circ} \mathrm{C}$, daripada suhu $30^{\circ} \mathrm{C}$, suhu $25^{\circ} \mathrm{C}$, dan suhu $20^{\circ} \mathrm{C}$. Howe (1956), menyatakan bahwa waktu perkembangan pupa $T$. castaneum pada suhu $20^{\circ} \mathrm{C}$ (24,4 hari) menunjukkan waktu perkembangan yang lebih lama daripada suhu $25^{\circ} \mathrm{C}$, suhu $30^{\circ} \mathrm{C}$, dan suhu $35^{\circ} \mathrm{C}$. Mason (2003), menyatakan bahwa suhu rendah dengan tingkat kelembaban yang tinggi dapat meningkatkan waktu perkembangan bagi Cryptolestes spp. Berdasarkan dua pernyataan tersebut sesuai dengan hasil penelitian yang menunjukkan bahwa kondisi suhu yang rendah dengan tingkat kelembaban yang optimum belum tentu dapat mempercepat waktu perkembangan perkembangan $C$. ferrugineus dari setiap fase hidupnya.

Terdapat beberapa faktor penting yang mempengaruhi lama perkembangan dari serangga hama $C$. ferrugineus salah satunya adalah suhu dan kelembaban (Abdelghany, 2017). Suhu yang tidak sesuai dengan kondisi kelembaban optimum juga dapat mengganggu waktu dari perkembangan telur hingga menjadi imago $C$. ferrugineus.
Ketidaksesuaian suhu dan kelembaban dapat memperlambat waktu perkembangan hingga mengakibatkan terputusnya fase dari serangga hama $C$. ferrugineus sehingga imago tidak dapat berkembang sempurna. Kondisi suhu dan kelembaban optimum bagi $C$. ferrugineus adalah $35^{\circ} \mathrm{C}$ dengan kelembaban $70 \%$ membutuhkan waktu untuk menyelesaikan siklus hidupnya selama 3 minggu (Rees, 2004). Telur C. ferrugineus berwarna bening berbentuk lonjong dengan ukuran panjang telur $0,53 \mathrm{~mm}$ dan diameter $0,16 \mathrm{~mm}$ biasanya diletakkan disisi biji atau bahan simpan di tempat penyimpanan Gambar 1. (Mason, 2003).

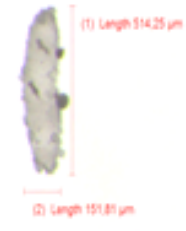

(a)

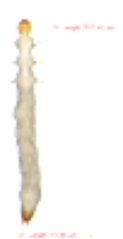

(b)

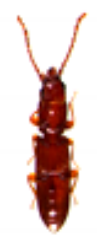

(c)
Gambar 1. (a)Telur, (b)Larva dan (c) Imago $C$. ferrugineus

Larva $C$. ferrugineus berukuran panjang 0,70 $\mathrm{mm}$ dan berwarna putih Gambar 1. Larva C. ferrugineus berbentuk silinder dan meruncing hingga segmen terakhir (Mason, 2003). Berdasarkan hasil penelitian waktu perkembangan C. ferrugineus dengan suhu $35^{\circ} \mathrm{C}$ dengan kelembaban $40 \%$ memerlukan waktu dari telur hingga menjadi imago selama 32 hari, sedangkan pada suhu $30^{\circ} \mathrm{C}$ dengan kelembaban $68 \%$ memerlukan waktu yang lebih singkat untuk berkembang menjadi imago selama 26,75 hari. Panjangnya waktu perkembangan telur hingga imago pada suhu $35^{\circ} \mathrm{C}$ diduga terjadi kerena kelembaban pada suhu tersebut jauh dibawah kondsi optimum bagi serangga hama C. ferrugineus. Berdasarkan kedua data tersebut menunjukkan bahwa suhu dan kelembaban yang berbeda dapat mempengaruhi waktu perkembangan dari telur hingga imago. Kisaran suhu bagi C. ferrugineus dapat menyelsaikan proses perkembangannya yaitu $20^{\circ} \mathrm{C}-42,5^{\circ} \mathrm{C}$ dengan lama waktu perkembangan yang berbeda-beda (Rees, 2004). Berdasarkan hasil penelitian yang dilakukan pada suhu $40^{\circ} \mathrm{C}$ dengan kelembaban $35 \%$ telur yang hasilkan oleh imago betina C. ferrugineus tidak menetas menjadi larva, sehingga fase $C$. ferrugineus terputus pada suhu $40^{\circ} \mathrm{C}$. Kenampakan telur yang berada pada suhu $40^{\circ} \mathrm{C}$ kering dan berwarna coklat kegelapan akibat kondisi kelembaban yang terlalu rendah. Terputusnya fase perkembangan dari $C$. ferrugineus dapat mempengaruhi jumlah dari larva, pupa dan imago sehingga dapat digunakan sebagai 
teknik untuk mengendalikan serangan imago $C$. ferrugineus.

Kerusakan yang ditimbulkan oleh imago $C$. ferrugineus menyebabkan biji atau bahan simpan retak menjadi tidak utuh, dalam kondisi yang parah bahan simpan berubah menjadi tepung dan memilki aroma tidak sedap. Kerusakan ini menyebabkan biji atau bahan simpan tidak layak konsumsi sehingga serangan ini akan menjadi buruk apabila imago $C$. ferrugineus berada dalam jumlah yang tinggi di tempat penyimpanan.

Larva C. ferrugineus juga melakukan serangan terhadap biji atau bahan simpan namun, serangan yang ditimbulkan tidak separah serangan imago. Imago $C$. ferrugineus sebagai serangga hama sekunder menyerang bahan simpan yang kondisinya sudah mengalami kerusakan akibat seranggan hama primer atau kerusakan akibat ketidaksesuaian penyimpan. Terputusnya fase perkembangan dari C. ferrugineus pada suhu $40^{\circ} \mathrm{C}$ akan mengurangi jumlah imago yang baru muncul sehingga akan berdampak pada serangan baru yang ditimbulkan pada bahan simpan.

Waktu perkembangan telur, larva dan pupa $C$. ferrugineus pada beberapa tingkatan suhu ruang yang berbeda menunjukan perbedaan yang nyata. Astuti (2013), menyatakan bahwa waktu perkembangan Rhyzopertha dominica dari telur hingga muncul imago baru dipengaruhi oleh tingkatan suhu dan kelembaban relatif. Waktu perkembangan yang diperlukan serangga hama dari telur hingga muncul imago baru berbeda-beda pada setiap tingkatan suhu ruang dan tingkat kelembaban. Kumawat (2007), menyatakan bahwa $R$. dominica mencapai pertumbuhan maksimum pada suhu $30,1^{\circ} \mathrm{C}$. Rees (2004), menyatakan bahwa akan terjadi penambahan waktu perkembangan saat diletakan pada kondisi suhu yang tidak optimum bagi pertumbuhan serangga hama gudang.

\section{KESIMPULAN}

Perkembangan $C$. ferrugineus pada suhu ruang $30^{\circ} \mathrm{C}$ dengan keembaban $68 \%$ lebih baik dengan menunjukan waktu perkembangan lebih singkat (26,75 hari) daripada suhu $35^{\circ} \mathrm{C}(32,00$ hari), suhu $20^{\circ} \mathrm{C}(40,50)$, suhu $25^{\circ} \mathrm{C}(42,50)$ dan pada suhu ruang $40^{\circ} \mathrm{C}$ telur $C$. ferrugineus tidak dapat menetas menjadi larva sehingga fase perkembangan pada suhu tersebut terputus.

\section{REFERENSI DAN SITASI}

Abdelghany, A. Y., Paul, G. F. 2017. Mortality and movement of Cryptolestes ferrugineus and Rhyzopertha dominica in response to cooling in $300-\mathrm{kg}$ grain bulks. Journal of Stored Products Research 71: 119-124

Abebe, F., T. Tefera, S. Mugo, Y. Beyene and S. Vidal. 2009. Resistence of Maize Varieties of the Maize Weevil S. zeamais. African Journal of Biotechnology. 8. (21) : 5937-5943.

Andales, S.C. 1988. "Summary Rerquirements for Safe Grain Storage". In Semple R.L. et al. (Ed). Towards Integrated Commodity and Pest Management in Grain Storage. Proceedings and Selected Papers from the Regional Training Course on Integrated Pest Management Strategies in Grain Storage Systems. Philippines: National Post Harvest Institute for Research and Extension (NAPHIRE), Departement of Agriculture.

Astuti, L. P., G. Mudjiono, S. Rasminah and B. T. Rahardjo. 2013. Influence of Temperature and Humidity on the Population Growth of Rhyzopertha dominica (f.) (Coleoptera: Bostrichidae) on Milled Rice. Journal of Entomology. 10. (2) : 86-94.

Bekele, J. A., D. Obengofori, A. Hassanali and G. H. N. Nyamasyo, 1995. Products Derived from the Leaves of Ocimum kilimandscharicum as Post-Harvest Grain Protectants Againts the Infestation of Three Major Stored Product Insect Pests. Bulletin Entomology. Res., 85: 361-367.

Eliopoulos, P.A., Prasodimou, G.Z., Pouliou, A.V., 2011. Time mortality relationships of larvae and adults of grain beetles exposed to extreme cold. Crop Prot. 30, 1097-1102.

Fields, P.G., 1992. The control of stored-product insects and mites with extreme temperature. J. Stored Prod. Res. 28, 89-118.

Fields, P.G., White, N.D.G., 1997. Survival and multiplication of stored-product beetles at simulated and actual winter temperatures. Can. Entomol. 129, 887-898.

Flinn, P.W., Hagstrum, D.W., 1998. Distribution of Cryptolestes ferrugineus (Coleoptera: Cucujidae) in response to temperature gradients in stored wheat. J. Stored Prod. Res. 34, 107-112.

Howe, R. W. 1956. The Effect of Temperature and Hunidity on Rate of Development and Mortality of Tribolium Castaneum (Herbest) (Coleoptera : Tenebrionidae). Annual Applied Biology. 44 (2), 356368 )

Jian, F., Jayas, D., White, N.D.G., 2004. Movement and distribution of adult rusty grain beetle, Cryptolestes ferrugineus (Coleoptera: Laemophloeidae), in stored wheat in response to different temperature gradients and insect densities. J. Econ. Entomol. 97, 1148e1158

Kawamoto, H. 1989. Effect of Temperature on Adult Survival and Potential Fecundity of The Rusty Grain Beetle Cryptolestes ferrugineus. Japanese Society of Applied Entomology and Zoology 24 : 418-423.

Kumawat, K. C. 2007. Effect of Abiotic Factors on Biology of Rhyzopertha dominica on Wheat. Annual Plant Protection Science. 15: 111-115

Lee Jr., R.E., 1991. Principles of insect low temperature tolerance. In: Lee Jr., R.E., Denlinger, D.L. (Eds.), Insects at Low 
Temperature. Chapman and Hall, New York, pp. 17-46.

Mason, L.J., Strait, C.A., 1998. Stored product integrated pest management with xtreme temperatures. In: Denlinger, D.L., Yocum, G.D. (Eds.), Physiology of Heat Sensetitive. Westview Press, Boulder, pp. 7-57.

Mason, L. J. 2003. Grain Insect Fact Sheet E-227W: Rusty, Flat, and Flour Mill Beetles Cryptolestes spp. Purdue University, Department of Entomology.

Rees, D. 2004. Insects of Stored Products. CSIRO Publishing, Collingwood, Australia.

Rilett, R.O., 1949. The biology of Laemophloeus ferrugineus (Steph). Can. J. Res. 27, 112-148.

Sinha, R.N., Watters, F.L., 1985. Insect Pests of Flour Mills, Grain Elevators, and Feed Mills and Their Control. Research Branch, Agriculture Canada Publication 1776, Ottawa, Ontario.

Smith, L.B., 1965. The intrinsic rate of natural increase of Cryptolestes ferrugineus (Stephens) (Coleoptera: Cucujidae). J. Stored Prod. Res. 1, 35e49.

Syarief, R dan H. Halid. 1993. Teknologi Penyimpanan Pangan. Jakarta: Penerbit Arcan. 
